\title{
Graphene dispersed cellulose microfibers composite for efficient immobilization of hemoglobin and selective biosensor for detection of hydrogen peroxide
}

Vijayalakshmi Velusamy ${ }^{\mathrm{a} *}$, Selvakumar Palanisamy ${ }^{\mathrm{b}}$, Shen-Ming Chen $^{\mathrm{b} * *}$, Tse-Wei Chen ${ }^{\mathrm{b}}$, Sonadevi Selvam ${ }^{\mathrm{c}}$, Sayee Kannan Ramaraj ${ }^{\mathrm{d}}$, Bih-Show Lou $^{\mathrm{e} * * *}$

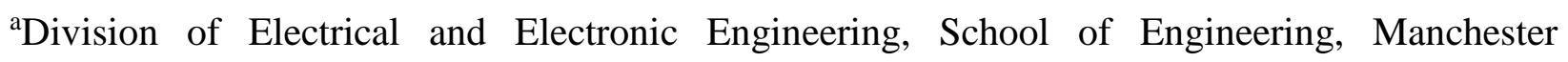
Metropolitan University, Manchester - M1 5GD, United Kingdom.

${ }^{\mathrm{b}}$ Electroanalysis and Bioelectrochemistry Lab, Department of Chemical Engineering and Biotechnology, National Taipei University of Technology, No. 1, Section 3, Chung-Hsiao East Road, Taipei 106, Taiwan.

'Department of Chemistry, PSR Engineering College, Sevalpatti, Sivakasi-626140.

d*PG \& Research department of Chemistry, Thiagarajar College, Madurai-09, Tamilnadu, India.

${ }^{\text {e}}$ Chemistry Division, Center for Education, Chang Gung University, 259, Wen-Hwa 1st Road, Kwei-Shan, Tao-Yuan 333, Taiwan, ROC

Corresponding authors

*V. Velusamy, E-mail: V.Velusamy@mmu.ac.uk

**S.M. Chen, E-mail: smchen78@ms15.hinet.net

*** B.S. Lou, E-mail: blou@ mail.cgu.edu.tw 


\begin{abstract}
In the present work, we have investigated the electrochemical behavior and electrocatalysis of hemoglobin $(\mathrm{Hb})$ immobilized on a glassy carbon electrode (GCE) modified with a graphenecellulose microfiber (GR-CMF) composite. The GR-CMF composite was characterized by scanning electron microscopy, elemental analysis, and Raman and Fourier transform infrared spectroscopy. Well-defined electrochemical redox characteristics of $\mathrm{Hb}$ were observed for $\mathrm{Hb}$ immobilized on a GR-CMF composite modified GCE, with a formal potential of $-0.306 \mathrm{~V}$ and a peak to peak separation of approximately $67 \mathrm{mV}$. Due to the high biocompatibility of the GRCMF composite, the electrochemical behavior of the $\mathrm{Hb}$ heme redox couple $\left(\mathrm{Fe}^{\mathrm{II}} / \mathrm{Fe}^{\mathrm{III}}\right)$ was enhanced for $\mathrm{Hb}$ immobilized on the GR-CMF composite when compared to $\mathrm{Hb}$ immobilized on pristine GR. The heterogeneous electron transfer constant $\left(\mathrm{k}_{\mathrm{s}}\right)$ was calculated as $6.17 \mathrm{~s}^{-1}$, and is higher than previously reported for $\mathrm{Hb}$ immobilized GR supports. The Hb immobilized GR-CMF composite modified electrode was used for the quantification of $\mathrm{H}_{2} \mathrm{O}_{2}$ under optimal conditions, and shows a wider linear amperometric response ranging from 0.05 to $926 \mu \mathrm{M}$. The limit of detection of the biosensor was $0.01 \mu \mathrm{M}$ with the sensitivity of $0.49 \mu \mathrm{A} \mu \mathrm{M}^{-1} \mathrm{~cm}^{-2}$. The biosensor also showed high selectivity in the presence of the range of interfering compounds and exhibits good operational stability and practicality in the detection of $\mathrm{H}_{2} \mathrm{O}_{2}$.
\end{abstract}

Keywords: Graphene; cellulose microfibers; direct electrochemistry; hemoglobin; biosensor; $\mathrm{H}_{2} \mathrm{O}_{2}$ 


\section{Introduction}

Recent advances in the nanomaterials indicate a wide range of promising applications for their use in biosensor systems [1] as commonly applied to the detection of toxins and pathogens in food, clinical, and environmental analysis $[2,3]$. Given their high specificity, biosensors based on heme redox proteins are widely used for detection of small molecules such as hydrogen peroxide $\left(\mathrm{H}_{2} \mathrm{O}_{2}\right)$ and nitrite $\left(\mathrm{NO}_{2}^{-}\right)$in food and environmental samples [4]. Demonstrating greater stability than other commercially available redox heme proteins such as horseradish peroxidase, cytochrome $\mathrm{C}$, and myoglobin, hemoglobin $(\mathrm{Hb})$ is ideal for biosensor applications $[\mathbf{5}, \mathbf{6}]$. Hbbased biosensors are particularly suited to the selective detection of $\mathrm{H}_{2} \mathrm{O}_{2}$ due to their high electrocatalytic activity and narrow target specificity. The accurate detection of $\mathrm{H}_{2} \mathrm{O}_{2}$ in food, biological and pharmaceutical samples is fundamental to a wide range of industrial applications [7-10]. However, effective immobilization of $\mathrm{Hb}$ on the electrode surface is a limiting factor in the efficiency of $\mathrm{Hb}$ based biosensors. Accordingly, different micro and nanomaterials or approaches have been explored as a means to anchor the redox active center of $\mathrm{Hb}$ to the electrode matrix.

Over recent years, carbon nanomaterials [11-13], metal oxides [14], metal nanoparticles [15], ionic liquids [16] and conducting polymers [17] have been utilized as immobilization matrices for $\mathrm{Hb}$. In particular, the 2D carbon nanomaterial graphene (GR) exhibits electronic conductivity and thermal stability superior to other carbon nanoforms $[\mathbf{1 8}, \mathbf{1 9}]$, and make it an ideal support material in the fabrication of biosensors $[\mathbf{1 9}, \mathbf{2 0}]$. However, the direct immobilization of $\mathrm{Hb}$ on pristine GR surface is problematic due to the molecules hydrophobic nature, and the $\mathrm{Hb}$ redox active center is located deep within the proteins tertiary structure [21]. Accordingly, the immobilization of redox active proteins such as $\mathrm{Hb}$ has necessitated modification of GR with appropriate biocompatible materials. For instance, carbohydrate polymers and supramolecular 
adducts are widely used as a dispersing agent for GR and the resulting composite may enrich the biocompatibility of GR for immobilization of redox active proteins [22-26]. As a natural, renewable, abundant, and biodegradable carbohydrate polymer, cellulose has been utilized in a wide range of industrial and medical applications [27]. In particular, hydrophobic, water insoluble cellulose microfibers $(\mathrm{CMF})$ represent a promising biomaterial for enzyme immobilization in biosensors due to their unique chemical properties and high biocompatibility [27]. In addition, CMF exhibits a high surface area, high porosity, and bond with the variety of conductive materials [27-30]. In the present work, we have exploited the aforementioned properties of CMF and, by dispersing GR in a CMF aqueous solution, prepared a GR CMF composite for the immobilization of $\mathrm{Hb}$. In doing so, the inherent nature of the hydrophilic CMFs acts to effectively prevent aggregation of GR and form a stable GR-CMF composite for immobilization of $\mathrm{Hb}$.

A review of the published literature indicates the great majority of GR and cellulose composites have been prepared by chemical reduction of graphene oxide and cellulose [28-30], but none have demonstrated the direct preparation of GR-CMF composite. However, we have recently demonstrated the direct preparation of GR-CMF composite as an immobilization matrix for laccase [31]. In the present work, we evaluate the electrochemical redox characteristics of $\mathrm{Hb}$ immobilized on a GR-CMF composite modified electrode and discuss this in relation to comparable modified electrodes for the immobilization of $\mathrm{Hb}$. An $\mathrm{H}_{2} \mathrm{O}_{2}$ biosensor was fabricated based on the $\mathrm{Hb}$ immobilized GR-CMF composite modified electrode, and the detection parameters quantified using an amperometric method.

\section{Experimental}

\subsection{Material and methods}


The cellulose microfibers (medium) powder was purchased from Sigma Aldrich. Graphene $8 \mathrm{~nm}$ nanoflakes were obtained from UniRegion Bio-Tech, Taiwan. $\mathrm{H}_{2} \mathrm{O}_{2}(30 \%)$ was received from Wako Pure Chemical Industries. Human blood serum samples were received from valley biomedical, Taiwan product \& services Inc., and was approved by the ethics committee of Chang-Gung memorial hospital in contract no. IRB101-5042A3. Commercial contact lens cleaning solution was purchased from China Chemical and Pharmaceutical, Taipei, Taiwan. The whole milk was purchased from a local department store in Taipei, Taiwan. The supporting electrolyte was $\mathrm{pH} 7$ phosphate buffer and was prepared with $0.05 \mathrm{M} \mathrm{Na}_{2} \mathrm{HPO}_{4}$ and $\mathrm{NaH}_{2} \mathrm{PO}_{4}$ in double distilled water. Adjustments to $\mathrm{pH}$ were made with $0.1 \mathrm{M} \mathrm{H}_{2} \mathrm{SO}_{4}$ and $0.1 \mathrm{M} \mathrm{NaOH}$.

The surface morphologies of the as-prepared materials were characterized using an Hitachi S-4300SE/N High Resolution Schottky Analytical VP scanning electron microscope (SEM). Elemental analysis (EDS) and elemental mapping of the composite were performed using Hitachi S-4300SE/N High Resolution Schottky Analytical VP SEM attached BRUKER AXS elemental analyzer. Fourier transform infrared (FTIR) spectroscopy was acquired using a JASCO FTIR-6600 spectrometer. Raman spectra for the materials were taken using a Dong Woo 500i Raman spectrometer equipped with a charge-coupled detector. Cyclic voltammograms and amperograms (amperometric $i$ - $t$ curve) were taken using CHI1205B electrochemical workstation from $\mathrm{CH}$ Instruments. $\mathrm{Hb}$ immobilized on a GR-CMF modified glassy carbon electrode (GCE) was used as a working electrode, where the apparent electrode surface of the GCE was approximately $0.079 \mathrm{~cm}^{2}$. Saturated $\mathrm{Ag} \mid \mathrm{AgCl}$ and $\mathrm{Pt}$ wire were used as a reference and auxiliary electrodes respectively. Amperometric $i-t$ measurements were performed using a PRDE-3A (ALS Co., Ltd, Japan) rotating ring disc electrode (RDE), in which the geometric area of the electrode is $0.08 \mathrm{~cm}^{2}$. The electrochemically active surface area (EASA) of the GR-CMF composite 
modified RDE was calculated as $0.27 \mathrm{~cm}^{2}$, and was calculated using Randles-Sevcik equation by cyclic voltammetry response of $1 \mathrm{mM}$ ferricyanide with $0.05 \mathrm{M} \mathrm{KCl} \mathrm{[32].}$

\subsection{Fabrication of the biosensor}

To fabricate the biosensor, first, the GR-CMF composite was prepared by dispersing GR ( $5 \mathrm{mg} \mathrm{mL}^{-1}$ ) into the CMF solution using ultrasonication for approximately $30 \mathrm{~min}$. The stable CMF solution was prepared by the addition of $10 \mathrm{mg} \mathrm{mL}^{-1}$ of CMF into the doubly distilled water and sonicated for $45 \mathrm{~min}$ at $10^{\circ} \mathrm{C}$. Then, about $6 \mu \mathrm{L}$ of GR-CMF composite solution was dropped on pre-cleaned GCE and allowed to dry in an air oven. Once dry, $6 \mu \mathrm{L}$ of Hb solution (optimum) was dropped on the as-prepared GR-CMF composite modified electrode and dried at room temperature. Then, the resulting $\mathrm{Hb}$ immobilized GR-CMF (GR-CMF/Hb) composite modified electrode was used for further electrochemical studies. The schematic representation of the biosensor fabrication is shown in Scheme 1. The fresh Hb stock solution was prepared by dissolving $5 \mathrm{mg} \mathrm{mL}^{-1}$ of $\mathrm{Hb}$ at $\mathrm{pH} 7$ and was stored at $-4^{\circ} \mathrm{C}$ when not in use. The $\mathrm{Hb}$ immobilized GR modified electrode was prepared by drop coating of $6 \mu \mathrm{L}$ of Hb solution on GR modified

electrode, while the GR dispersion was prepared by dispersing of $5 \mathrm{mg} \mathrm{mL}^{-1}$ of GR into the dimethylformamide (DMF) using ultrasonication for $30 \mathrm{~min}$. The $\mathrm{Hb}$ immobilized $\mathrm{CMF}$ modified electrode was prepared by the same method. Optical images of GR-DMF, CMF and GR-CMF composite are shown in Fig. 1D. All electrochemical measurements were performed in oxygen-free atmosphere by purging high purity $\mathrm{N}_{2}$ into $\mathrm{pH} 7$ for at least $10 \mathrm{~min}$, and the modified electrodes were stored under the dry condition when not in use.

\section{Results and discussion}

\subsection{Characterizations}


The surface morphological studies of the GR, CMF, and as-prepared GR-CMF composite were characterized by high-resolution SEM. Fig. 1 shows SEM images of pristine GR (A), CMF, (B) and GR-CMF composite (C). The SEM images shows the closely arranged layering of relatively small individual pristine GR nanosheets, and the typical dense fiber morphology of CMF. It is clear from Fig. 1C that the GR nanosheets were highly exfoliated by CMF compared with pristine GR. In addition, the optical image of GR-CMF composite (Fig. 1D) confirms the formation of GR-CMF composite and CMF is a suitable dispersing agent for GR. The GR-CMF composite was found to be highly stable even after storage for six days. We also performed EDS and elemental mapping of the GR-CMF composite and the results are shown in Fig. S1 and Fig. 2A and B. The EDS and elemental mapping of GR-CMF composite confirm the presence of carbon and oxygen in the composite, while oxygen is absent in the EDS and elemental mapping of pristine GR (not shown). The result also supports formation of GR-the CMF composite.

FTIR spectroscopy has been a powerful tool to investigate the different functional groups present in the compounds and interactions between the compounds in the composite. Fig. 3A shows the FTIR spectra of GR (a), CMF (b) and GR-CMF (c). The FTIR spectrum of CMF shows a characteristic vibration band at $3300-3500 \mathrm{~cm}^{-1}$, and corresponding to stretching vibrations of the $\mathrm{OH}$ group [31]. Analysis of CMF showed two additional bands at 2892 and $1652 \mathrm{~cm}^{-1}$, due to stretching of $\mathrm{CH}$ and $\mathrm{CH}_{2}$, and $\mathrm{OH}$ from absorbed water [31]. The FTIR spectrum of GR was found to be featureless in the finger print region and is similar to that previously reported for GR [25]. However, the FTIR spectrum of GR-CMF composite showed a similar characteristic band those compared with the FTIR spectrum CMF, which confirms the firm attachment of CMF to the GR surface. 
Raman spectroscopy is widely used to study the allotropes of carbon, especially GR nanostructures, due to its sensitive nature to a positioning of the carbon atoms. As shown in Fig. 3B, the Raman spectra of GR and GR-CMF exhibits a strong G band at 1592 and $1591 \mathrm{~cm}^{-1}$, and due to the in-plane vibrational modes of $\mathrm{sp}^{2}$ hybridized carbon atoms on GR [25]. The less

intense $\mathrm{D}$ band at 1888 and $1387 \mathrm{~cm}^{-1}$, is ascribed to the vibrations of $\mathrm{sp}^{3}$ carbon atoms of disordered GR and vibrations of $\mathrm{sp}^{2}$ carbon atom domains of graphite [33]. Usually, the D band is less active and G band is highly active in few-layered GR than multi layered GR sheets. The 2D bands of were observed at $2726 \mathrm{~cm}^{-1}$ and $2724 \mathrm{~cm}^{-1}$ on GR and GR-CMF composite, is due to the two phonon lattice vibrational process on GR sheets [33]. Peak intensity ratio $\left(\mathrm{I}_{2 \mathrm{D}} / \mathrm{I}_{\mathrm{G}}\right)$ of the 2D and G bands of GR and GR-CMF was found as 0.92 and 0.91 . The result confirms that GRCMF composite has few layered GR sheets with less defects than pristine GR.

\subsection{Electrochemical behavior of $\mathrm{Hb}$ at different modified electrodes}

The redox activity site of $\mathrm{Hb}$ is acknowledged as the cofactor heme $\left(\mathrm{Fe}^{\mathrm{II}} / \mathrm{Fe}^{\mathrm{III}}\right)$ and is responsible for its direct electrochemical behavior on the electrode surface. Hence, we have investigated the electrochemical behavior of $\mathrm{Hb}$ immobilized at the surface of different modified electrodes by $\mathrm{CV}$. The $\mathrm{CV}$ measurements were carried out in $\mathrm{N}_{2}$ atmosphere with a scan rate of $100 \mathrm{mV} / \mathrm{s}$ and a potential range of -0.7 to $0.2 \mathrm{~V}$. The electrochemical response of $\mathrm{Hb}$ immobilized at CMF (a), GR (b), and GN-CMF composite (c) modified electrodes is shown in Fig. 4. The Hb immobilized CMT modified electrode did not show the redox behavior we expected for $\mathrm{Hb}$, and shows only a cathodic peak response at $-0.306 \mathrm{~V}$ with reversible anodic peak. This result indicates that electrochemical redox of $\mathrm{Hb}$ is not favorable at the $\mathrm{CMF}$ modified electrode. A less intense electrochemical redox behavior of $\mathrm{Hb}$ was observed for the GR modified electrode and the anodic and cathodic peak potentials were located at -0.362 and $-0.282 \mathrm{~V}$. The peak-to-peak separation 
was $80 \mathrm{mV}$. However, the electrochemical redox behavior of $\mathrm{Hb}$ was greatly enhanced when immobilized on the GR-CMF modified electrode, with a redox current intensity 3 fold higher than observed on GR. The anodic and cathodic peak of redox couple was located at -0.372 and 0.242 $\mathrm{V}$, with the peak-to-peak separation of $130 \mathrm{mV}$. The result indicates the direct electrochemical behavior of $\mathrm{Hb}$ to be greatly enhanced on GR-CMF composite when compared to $\mathrm{Hb}$ immobilized on pristine GR. The good biocompatibility of CMF provides a suitable matrix for orientation of $\mathrm{Hb}$ on the composite electrode surface. As shown in Fig. S2a, the GR-CMF composite did not show any obvious response in the absence of $\mathrm{Hb}$, which indicates the redox electrochemical activity to be dependent on the presence of a $\mathrm{Hb}$ heme.

The surface concentration $\left(\mathrm{I}^{-}\right)$of immobilized $\mathrm{Hb}$ on GR-CMF composite modified electrode was determined as $0.45 \times 10^{-10} \mathrm{~mol} \mathrm{~cm}^{-2}$ and was calculated using Q/nFA. Where $\mathrm{Q}$ is the total charge, $\mathrm{n}$ is the number of electrons transferred in the redox reaction, $\mathrm{F}$ is the Faraday constant, and $\mathrm{A}$ is the electrochemically active surface area of the biosensor. The obtained $\mathrm{I}^{-}$value of the biosensor is higher than that of previously reported for $\mathrm{Hb}$ immobilized on nanomaterial modified electrodes [34-37], and indicates a greater efficiency of Hb molecules adsorption on the composite electrode surface. We have also performed $\mathrm{CV}$ to determine the effect of scan rate (ranging from 50 to $1000 \mathrm{mV} / \mathrm{s}$ ) on the electrochemical redox behavior of the $\mathrm{Hb}$ immobilized GR-CMF modified electrode. As shown in Fig. S3A, the redox peak current of $\mathrm{Hb}$ increases with the scan rate, and corresponding potentials showed a greater degree of positive and negative shift as the scan rate increased from 50 to $1000 \mathrm{mV} / \mathrm{s}$. We have also made the plot for scan rate vs. anodic and cathodic peak current of $\mathrm{Hb}$ and the results are shown in Fig. S3B. It can be seen that the anodic and cathodic redox peak current of $\mathrm{Hb}$ has a linear dependence on the scan rate. The linear regression equations were expressed as: $I_{p a}(\mu A)=0.4446+2.9878 \mathrm{mV} / \mathrm{s}\left(R^{2}=0.9959\right)$ and 
$\mathrm{I}_{\mathrm{pc}}(\mu \mathrm{A})=-0.0419-0.8512 \mathrm{mV} / \mathrm{s}\left(\mathrm{R}^{2}=0.9975\right)$. The result indicates that the electrochemical redox behavior of $\mathrm{Hb}$ was a surface controlled electrochemical process on the GR-CMF composite electrode. Additionally, the Laviron equation was used to calculate the heterogeneous electron transfer rate constant $\left(\mathrm{k}_{\mathrm{s}}\right)$ of $\mathrm{Hb}$ immobilized GR-CMF composite modified electrode [34], as $6.63 \mathrm{~s}^{-1}$. This high $\mathrm{k}_{\mathrm{s}}$ value of the Hb immobilized GR-CMF composite indicates that the GR-CMF composite facilitates the direct electrochemical activity of the $\mathrm{Hb}$ heme, and facilitates fast direct electron transfer to the electrode surface. Furthermore, the calculated $\mathrm{k}_{\mathrm{s}}$ value is higher than previously reported $\mathrm{Hb}$ immobilized nanomaterials modified electrodes $[\mathbf{6}, \mathbf{7}, \mathbf{1 4}, \mathbf{2 6}, \mathbf{3 5}-\mathbf{3 8}]$, and indicates that GR-CMF composite is a more efficient $\mathrm{Hb}$ immobilization matrix than previously reported GR modified electrodes.

As a biomolecule, the direct electrochemical behavior of $\mathrm{Hb}$ is $\mathrm{pH}$ dependent. Hence, the effect of electrolyte $\mathrm{pH}$ on the electrochemical redox activity of $\mathrm{Hb}$ immobilized GR-CMF composite modified electrode was studied by CV (not presented here). Hb electrochemical activity was characterized in $\mathrm{N}_{2}$ saturated different $\mathrm{pH}(\mathrm{pH} 5,7,9$ and 11) at a scan rate of $100 \mathrm{mV} / \mathrm{s}$. The obtained results are plotted in Fig. S3C. The formal potential $\left(\mathrm{E}^{0^{\prime}}\right)$ of $\mathrm{Hb}$ shows a linear dependence over this $\mathrm{pH}$ range, and the linear regression equation was $\mathrm{E}^{0^{\prime}}=-0.0583+0.1167$ $\mathrm{V} / \mathrm{pH}$ with the correlation coefficient of 0.9887 . The obtained slope value $(-58.3 \mathrm{mV} / \mathrm{pH})$ is much closer to the reported theoretical value of the Nernstian equation for a reversible electrochemical process involving an equal number of electrons and protons [35]. The redox electrochemical mechanism of $\mathrm{Hb}$ was extensively studied on carbon nanomaterial modified electrodes, and our results are similar to the previous reports for a one proton and electron transferred redox reaction of the heme redox active center $[\mathbf{2 6}, \mathbf{3 5}]$.

\subsection{Electrocatalytic reduction of $\mathrm{H}_{2} \mathrm{O}_{2}$}


The electrocatalytic activity of $\mathrm{Hb}$ immobilized GR-CMF composite modified electrode was further examined by CV. Fig. S4 shows the CV response of biosensor in the absence (a) and presence (c) of $500 \mu \mathrm{M} \mathrm{H}_{2} \mathrm{O}_{2}$ into the PBS. A stable and well-defined redox couple of $\mathrm{Hb}$ was observed in the absence of $\mathrm{H}_{2} \mathrm{O}_{2}$. However, the cathodic peak current of the $\mathrm{Hb}$ heme was dramatically increased in the presence of $500 \mu \mathrm{M} \mathrm{H} \mathrm{H}_{2} \mathrm{O}_{2}$ due to the reduction of $\mathrm{H}_{2} \mathrm{O}_{2}$ by immobilized $\mathrm{Hb}$. In the absence of $\mathrm{Hb}$, the GR-CMF composite modified electrode did not show the obvious reduction peak current response to $\mathrm{H}_{2} \mathrm{O}_{2}$ (curve b), confirming the enhanced reduction current of $\mathrm{H}_{2} \mathrm{O}_{2}$ is due to the presence of heme redox active center of immobilized $\mathrm{Hb}$ on GR-CMF composite. The result indicates that $\mathrm{Hb}$ immobilized GR-CMF composite modified electrode can be used for sensitive and low potential detection of $\mathrm{H}_{2} \mathrm{O}_{2}$.

Amperometric $i-t$ method was used for the quantification of $\mathrm{H}_{2} \mathrm{O}_{2}$ using $\mathrm{Hb}$ immobilized GR-CMF modified electrode. The working potential of the biosensor was fixed at $-0.3 \mathrm{~V}$ and is close to the reduction potential of $\mathrm{H}_{2} \mathrm{O}_{2}$ by heme redox active center of $\mathrm{Hb}$ (Fig. S4). Under optimized conditions, the amperometric $i-t$ was performed for $\mathrm{Hb}$ immobilized GR-CMF modified RDE according to $\mathrm{H}_{2} \mathrm{O}_{2}$ concentration by additions of $\mathrm{H}_{2} \mathrm{O}_{2}$ into a constantly stirred $\mathrm{pH}$ 7. The obtained amperometric results are shown in Fig. 5A. It can be clearly seen that the biosensor exhibited a stable and well-defined amperometric response for the addition of different concertation of $\mathrm{H}_{2} \mathrm{O}_{2}$. As shown in the upper inset, the biosensor shows a stable response for the addition of $0.05,0.1,0.5,1.0,3.0$ and $5.0 \mu \mathrm{M} \mathrm{H}_{2} \mathrm{O}_{2}$. The response time of the biosensor was calculated as $4 \mathrm{~s}$, and indicates a fast electrocatalytic reduction of $\mathrm{H}_{2} \mathrm{O}_{2}$. As shown in the lower inset, the amperometric response of the biosensor was linear over the $\mathrm{H}_{2} \mathrm{O}_{2}$ concentrations ranging from 0.05 to $926 \mu \mathrm{M}$ with a correlation coefficient of 0.9965 . The limit of detection (LOD) of the biosensor was calculated as $0.01 \mu \mathrm{M}$ based on a signal-to-noise ratio equal to 3 ( $\mathrm{S} / \mathrm{N}=3$ ). The 
sensitivity of the biosensor was $0.49 \mu \mathrm{A \mu M}^{-1} \mathrm{~cm}^{-2}$ and was calculated using slope/EASA. We have compared the analytical performance of the as-prepared biosensor with previously reported enzymatic $\mathrm{H}_{2} \mathrm{O}_{2}$ sensors, and the results are shown in Table 1. The comparative results clearly show that our biosensor has a superior analytical performance (low LOD, high $\mathrm{k}_{\mathrm{s}}$, wider linear response range and sensitivity) towards the detection of $\mathrm{H}_{2} \mathrm{O}_{2}[\mathbf{1 6}, \mathbf{2 3}, \mathbf{2 6}, \mathbf{3 5}, \mathbf{3 9}-\mathbf{4 4}]$. Accordingly, the as-prepared biosensor is more suitable for the sensitive and low-level detection of $\mathrm{H}_{2} \mathrm{O}_{2}$. The high conductivity and biocompatibility of the GR-CMF composite provide a matrix suited to the immobilization of $\mathrm{Hb}$, and result in optimal $\mathrm{H}_{2} \mathrm{O}_{2}$ detection demonstrating a wider response range, greater sensitivity, lower LOD, and a fast response. The catalytic activity and enzyme-substrate kinetics of immobilized $\mathrm{Hb}$ on GR-CMF composite was evaluated using Michaelis Menten constant $\left(\mathrm{K}_{\mathrm{M}}{ }^{\text {app }}\right)$, and was calculated from the Lineweaver-Burk equation $\left(1 / \mathrm{I}_{\mathrm{ss}}=1 / \mathrm{I}_{\max }+\right.$ $\left.\mathrm{K}_{\mathrm{M}}^{\mathrm{app}} /\left(\mathrm{I}_{\max } \mathrm{C}\right)\right)$. The reciprocal of the steady-state current $\left(\mathrm{I}_{\mathrm{ss}}\right)$ vs. reciprocal of $\left[\mathrm{H}_{2} \mathrm{O}_{2}\right]$ was plotted, and showed that $\mathrm{I}_{\mathrm{ss}}$ had a linear relationship with the reciprocal of $\left[\mathrm{H}_{2} \mathrm{O}_{2}\right]$ with a correlation coefficient of 0.9957 . The $\mathrm{K}_{\mathrm{M}}^{\text {app }}$ was determined from the obtained slope (11.555) and intercept (0.028), where slope and intercept is equal to $\mathrm{K}_{\mathrm{M}}^{\text {app }} / \mathrm{I}_{\max }$ and $1 / \mathrm{I}_{\max }$. The apparent $\mathrm{K}_{\mathrm{M}}^{\text {app }}$ was calculated as $413 \mu \mathrm{M}$. The obtained $\mathrm{K}_{\mathrm{M}}^{\text {app }}$ was higher than previously reported $\mathrm{Hb}$ immobilized graphene/carbon fiber $(80.0 \mu \mathrm{M})$ [16], graphene/chitosan $(344.0 \mu \mathrm{M})$ [23], graphene/zinc oxide/gold nanoparticles $(170.0 \mu \mathrm{M})$ [39], multi-walled carbon nanotubes-poly-l-histidine/zinc oxide $(140.0 \mu \mathrm{M})[41]$, graphene/ $\mathrm{Fe}_{3} \mathrm{O}_{4}(3.7 \mu \mathrm{M})[\mathbf{4 3}]$ and palladium nanoparticles/graphenechitosan $(16.0 \mu \mathrm{M})[44]$ modified electrodes. The high value of $\mathrm{K}_{\mathrm{M}}{ }^{\text {app }}$ indicates the high biological affinity of the biosensor towards $\mathrm{H}_{2} \mathrm{O}_{2}$.

\subsection{Selectivity of the biosensor}


Since $\mathrm{H}_{2} \mathrm{O}_{2}$ interacts with ascorbic acid, dopamine, uric acid, glucose, and L-cysteine, selectivity of the as-prepared biosensor was evaluated by amperometry in the presence of interfering species [26]. Fig. 5B shows the amperometric response of the $\mathrm{Hb}$ immobilized GRCMF modified electrode in response to the addition of $1 \mu \mathrm{M} \mathrm{H}_{2} \mathrm{O}_{2}$ (a), and $500 \mu \mathrm{M}$ additions of ascorbic acid (b), dopamine (c), uric acid (d), epinephrine (e), 1-cysteine (f), norepinephrine (g) and glucose (h) to $\mathrm{N}_{2}$ saturated $\mathrm{pH} 7$ with an operational working potential of $-0.3 \mathrm{~V}$. The biosensor showed a sharp and stable amperometric response for the addition of $1 \mu \mathrm{M} \mathrm{H}_{2} \mathrm{O}_{2}$ (a), while the addition of each interfering species elicited no discernible current response. These results indicates the high specificity of the biosensor is due to the high specificity of immobilized $\mathrm{Hb}$ and negative working potential $(-0.3 \mathrm{~V})$. Hence, the as-prepared biosensor is suited to the selective detection of $\mathrm{H}_{2} \mathrm{O}_{2}$ in environmental or clinical samples.

We have also investigated the operational stability of the biosensor by amperometry and the results are shown in Fig. 5C. The working conditions are similar to Fig. 5A. It can be seen that the amperometric background current response of the biosensor was $97.8 \%$ stable even after the continuously run up to $2000 \mathrm{~s}$ in $\mathrm{pH} 7.0$, and reflecting the highly stable nature of $\mathrm{Hb}$ immobilized on the GR-CMF composite. The $\mathrm{CV}$ was further used to evaluate the repeatability and reproducibility of the biosensor for detection of $500 \mu \mathrm{M} \mathrm{H}_{2} \mathrm{O}_{2}$ and with the experimental conditions similar to Fig. S4. We used six independently prepared biosensors for the detection of $500 \mu \mathrm{M} \mathrm{H}_{2} \mathrm{O}_{2}$, and obtained a relative standard deviation (RSD) of approximately 4.3\%. By way of comparison, a single biosensor showed an RSD of $2.7 \%$ for detection of $500 \mu \mathrm{M} \mathrm{H}_{2} \mathrm{O}_{2}$ across 10 separate solutions. The observed RSD values of the biosensor are well within acceptable limits; hence the biosensor is suited to precise detection of $\mathrm{H}_{2} \mathrm{O}_{2}$. The fabricated biosensor was also tested for long-term storage stability (up to 35 days) by $\mathrm{CV}$ and was stored at $4{ }^{\circ} \mathrm{C}$ under dry conditions. 
The prepared biosensor was tested for every five days by $\mathrm{CV}$ in response to $500 \mu \mathrm{M} \mathrm{H}_{2} \mathrm{O}_{2}$ and experimental conditions similar to Fig. S4. As shown in Fig. S5, the as-prepared biosensor retained 84.2 and $81.1 \%$ of its initial sensitivity after the 20 and 35 days storage respectively, which indicating excellent stability.

\subsection{Determination of $\mathrm{H}_{2} \mathrm{O}_{2}$ in food, biological and pharmaceutical samples}

As a proof of concept, we have evaluated the biosensors performance in amperometric determination of $\mathrm{H}_{2} \mathrm{O}_{2}$ in real samples. The amperometric experimental conditions are similar to Fig. 5A. We have used whole milk, contact lens cleaning solution $\left(3 \% \mathrm{H}_{2} \mathrm{O}_{2}\right)$ and human serum for the real sample analysis. The whole milk and human serum samples were $\mathrm{H}_{2} \mathrm{O}_{2}$ free and used as received. The contact lens cleaning solution was diluted with $\mathrm{pH} 7$ and the unknown concentration of $\mathrm{H}_{2} \mathrm{O}_{2}$ was determined using the as-prepared biosensor. Known concentrations of $\mathrm{H}_{2} \mathrm{O}_{2}(1.0$ and $2.0 \mu \mathrm{M})$ contained in whole milk, contact lens cleaning solution, and human serum were injected into the $\mathrm{pH} 7$ phosphate buffer and their recoveries were calculated using a standard addition method. The obtained recoveries of $\mathrm{H}_{2} \mathrm{O}_{2}$ were summarized in Table S1. The average recoveries of $\mathrm{H}_{2} \mathrm{O}_{2}$ were $93.0,98.5$ and $99.0 \%$ with a RSD of $3.5,3.1$ and $2.8 \%$ in whole milk, contact lens cleaning solution, and human serum samples respectively. The good recovery and appropriate RSD of the biosensor further validates that it the application of the biosensor for realtime detection of $\mathrm{H}_{2} \mathrm{O}_{2}$ in food, biological and pharmaceutical samples.

\section{Conclusions}

In summary, we have developed a sensitive and selective $\mathrm{H}_{2} \mathrm{O}_{2}$ biosensor based on the electrochemical redox behavior of $\mathrm{Hb}$ immobilized on GR-CMF composite. Physicochemical characterizations confirms the formation of the GR-CMF composite. The combined unique properties of GR-CMF composite facilitates the direct electron transfer between $\mathrm{Hb}$ and electrode 
than GR and CMF modified electrodes. The as-prepared biosensor exhibits good electrocatalytic activity and analytical performance (low LOD $(10 \mathrm{nM})$, high sensitivity $\left(0.49 \mu \mathrm{A} \mu \mathrm{M}^{-1} \mathrm{~cm}^{-2}\right)$, fast response $(\sim 3 \mathrm{~s}$ ) and a broad linear response range (up to $926 \mu \mathrm{M})$ ) towards $\mathrm{H}_{2} \mathrm{O}_{2}$. The biosensor performance for real samples demonstrates its suitability to real time monitoring of $\mathrm{H}_{2} \mathrm{O}_{2}$ in food, biological and pharmaceutical samples. The presented research points the way for the development of further biosensors based on the superior immobilization efficiency and electron transfer characteristics of the GR-CMF composite.

\section{Acknowledgement}

The Ministry of Science and Technology (MOST), Taiwan and Engineering and Materials Research Centre (EMRC), School of Engineering, Manchester Metropolitan University, Manchester, financially support the work.

\section{Conflict of interest}

We declare that we do not have any conflict of interest. 


\section{Reference}

[1] M. Holzinger, M., Le, A., Front. Chem., 2 (2014) 1-10.

[2] P. Mehrotra, J. Oral Biol. Craniofac. Res., 6 (2016) 15 3-1 59.

[3] E.P. Bahadır, M.K. Sezgintürk, Anal. Biochem., 478 (2015) 107-120.

[4] L. Luo, F. Kong, S. Chu, Y. Liu, H. Zhu, Y. Wang, Z. Zou, New J. Chem. 35 (2011) 28322839.

[5] Y. Liu, J. Gong, W. Wu, Y. Fang, Q. Wang, H. Gu, Sens. Actuators, B, 222 (2016) 588-597.

[6] Y. Liu, T. Han, C. Chen, N. Bao, C.M. Yu, H.Y. Gu, Electrochim. Acta, 56 (2011) 32383247.

[7] S.J. Yao, J.H. Xu, Y. Wang, X.X. Chen, Y.X. Xu, S.S. Hu, Anal. Chim. Acta, 557 (2006) 7884.

[8] O,S. Wolfbeis, A. Dürkop, M. Wu, Z.H. Lin, Angew. Chem. Int. Ed. 41 (2002) 4495-4498.

[9] C.G. Tsiafoulis, P.N. Trikalitis, M.I. Prodromidis, Electrochem. Commun. 7 (2005) 13981404.

[10] K.J. Chen, K.C. Pillai, J. Rick, C.J. Pan, S.H. Wang, C.C. Liu, B.J. Hwang, Biosens Bioelectron., 33 (2012) 120-127.

[11] P.A. Prakash, U. Yogeswaran, S.M. Chen, Talanta, 78 (2009) 1414-1421.

[12] J.W. Shie, U. Yogeswaran, S.M. Chen, Talanta, 78 (2009) 896-902.

[13] W. Sun, Y. Guo, X. Ju, Y. Zhang, X. Wang, Z. Sun, Biosens. Bioelectron., 42 (2013) 207213.

[14] S. Palanisamy, S. Cheemalapati, S.M. Chen, Anal. Biochem. 429 (2012) 108-115.

[15] S. Chen, R. Yuan, Y. Chai, F. Hu, Microchim. Acta, 180 (2013) 15-32.

[16] J. Bai, L. Wu, X. Wang, H.M. Zhang, Electrochim. Acta, 185 (2015) 142-147. 
[17] B. Zhou, R. Sun, X. Hu, L. Wang, H. Wu, S. Song, C. Fan, Int. J. Mol. Sci. 6 (2005) 303-310.

[18] J. Molina, RSC Adv., 6 (2016) 68261-68291.

[19] M.J. Allen, V.C. Tung, R.B. Kaner, Chem. Rev., 110 (2010) 132-145.

[20] Y. Shao, J. Wang, H. Wu, J. Liu, I.A. Aksay, Y. Lin, Electroanalysis, 22 (2010) 1027-1036.

[21] W. Sun, L. Cao, Y. Deng, S. Gong, F. Shi, G. Li, Z. Sun, Anal. Chim. Acta, 781 (2013) 4147.

[22] T. Kuila, S. Bose, P. Khanra, A.K. Mishra, N.H. Kim, J.H. Lee, Biosens. Bioelectron., 26 (2011) 4637-4648.

[23] H.F. Xu, H. Dai, G.N. Chen, Talanta 81 (2010) 334-338.

[24] L. Zhang, G. Han, Y. Liu, J. Tang, W. Tang, Sens. Actuators, B, 197 (2014) 164-171.

[25] L. Wang, X. Zhang, H. Xiong, S. Wang, Biosens. Bioelectron., 26 (2010) 991-995.

[26] S. Palanisamy, Y.T. Wang, S.M. Chen, B. Thirumalraj, B.S. Lou, Microchim. Acta, 183 (2016) 1953-1961.

[27] Y. Habibi, Chem. Soc. Rev., 43 (2014) 1519-1542.

[28] J.T. Korhonen, M. Kettunen, R.H.A. Ras, O. Ikkala, ACS Appl. Mater. Interfaces, 3 (2011) $1813-1816$.

[29] C. Zhang, R.Z. Zhang, Y.Q. Ma, W.B. Guan, X.L. Wu, X. Liu, H. Li, Y.L. Du, C.P. Pan, ACS Sustainable Chem. Eng. 3 (2015) 396-405.

[30] N.D. Luong, N. Pahimanolis, U. Hippi, J.T. Korhonen, J. Ruokolainen, L.S. Johansson, J.D. Namd, J. Seppala, J. Mater. Chem., 21 (2011) 13991-13998.

[31] S. Palanisamy, S.K. Ramaraj, S.M. Chen, T.C.K. Yang, P. Yi-Fan, T.W. Chen, V. Velusamy, S. Selvam, Sci Rep. 7 (2017) 41214. 
[32] S. Palanisamy, K. Thangavelu, S.M. Chen, B. Thirumalraj, X.H. Liu, Sens. Actuators, B, 233 (2016) 298-306.

[33] S.Y. Lee, S. Bang, S. Kim, S.Y. Jo, B.C. Kim, Y. Hwang, I. Noh, Biomater. Res. 19 (2015) 12.

[34] M. Baghdadi, A. Jafari, A. Pardakhti, RSC Adv., 6 (2016) 61423-61433.

[35] B. Thirumalraj, S. Palanisamy, S.M. Chen, K.D. Wael, J. Electrochem. Soc. 163 (2015) B265-B271.

[36] T. Mondal, A.K. Bhowmick, R. Krishnamoorti, J. Mater. Chem., 22 (2012) 22481.

[37] B. Habibi, M. Jahanbakhshi, Microchim. Acta, 182 (2015) 957.

[38] M.A. Aref, J.B. Raoof, F. Kiekens, K.D. Wael, Biosens. Bioelectron., 74 (2015) 518.

[39] L. Xie, Y. Xu, X. Cao, Colloids Surf., B, 107 (2013) 245-250.

[40] A. Banaei, H. Ghourchian, P. Rahimi, A.K.M. Movahedi, R. Amjadi, J. Iran. Chem. Soc. 12 (2015) 687-694.

[41] A.T. Ezhil Vilian, S.M. Chen, C.H. Kwak, S.K. Hwang, Y.S. Huh, Y.K. Han, Sens. Actuators, B 224 (2016) 607-617.

[42] X. Feng, R. Li, C. Hu, H. Wenhua, Electroanal. Chem. 657 (2011) 28-33.

[43] Y. He, Q. Sheng, J. Zheng, M. Wang, B. Liu, Electrochim. Acta, 56 (2011) 2471-2476.

[44] Sun, Q. Sheng, J. Zheng, Appl. Biochem. Biotechnol. 166 (2012) 764-773. 
Table 1 Comparison of the analytical performance of GR-CMF/Hb biosensor with the previously reported $\mathrm{Hb}$ based biosensors for the determination of $\mathrm{H}_{2} \mathrm{O}_{2}$.

\begin{tabular}{ccccccc}
\hline Biosensor & $\begin{array}{c}\mathbf{E}_{\text {app }} \\
(\mathbf{V})\end{array}$ & $\begin{array}{c}\text { LOD } \\
(\mathbf{n M})\end{array}$ & $\begin{array}{c}\text { LRR } \\
\text { upper limit } \\
(\boldsymbol{\mu M})\end{array}$ & $\begin{array}{c}\text { Ks } \\
(\mathbf{s})\end{array}$ & $\begin{array}{c}\text { Sensitivity } \\
\left(\boldsymbol{\mu} \mathbf{\mu} \mathbf{M}^{-\mathbf{1}} \mathbf{c m}^{-2}\right)\end{array}$ & Ref. \\
\hline Hb-MWCNT/ZnO/GCE & -0.34 & 20.0 & 516.0 & 1.26 & 3.66 & {$[26]$} \\
\hline Hb-GR-CS/GCE & -0.4 & 510.0 & 230.0 & NR & NR & {$[23]$} \\
\hline Hb-GR-GTN/GCE & -0.32 & 40.0 & 786.6 & 3.82 & 0.048 & {$[35]$} \\
\hline Hb-GR-CFE & -0.36 & 2000.0 & 210.0 & 1.93 & 1.4 & {$[16]$} \\
\hline Hb-GR/ZnO-AuNPs/GCE & -0.3 & 80.0 & 1130.0 & 1.3 & NR & {$[39]$} \\
\hline Hb-MWCNT-His-ZnO/GCE & -0.25 & 10.0 & 18000.0 & 5.16 & 0.021 & {$[41]$} \\
\hline Hb-Fe 3 O 4 -GR/CCE & -0.3 & 500.0 & 585.0 & 0.91 & NR & {$[42]$} \\
\hline Hb-GR-Pt/GCE & -0.26 & 1000.0 & 585.0 & 0.92 & NR & {$[43]$} \\
\hline Hb-GN/CS/PdNPs/GCE & NR & 660.0 & 1100.0 & 0.86 & 0.002 & {$[44]$} \\
\hline GR-CMF/Hb/GCE & -0.3 & 10 & 926 & 6.3 & 0.49 & Present work \\
\hline Abbreviations
\end{tabular}

\section{Abbreviations}

LRR - linear response range; LOD - limit of detection; MWCNT - multi-walled carbon nanotubes;

GCE - glassy carbon electrode; NR - not reported; GR - graphene; CS - chitosan; GTN - gelatin;

CFE - carbon fiber electrode; NPs - nanoparticles; His - histidine; GN - graphene 


\section{Biographies}

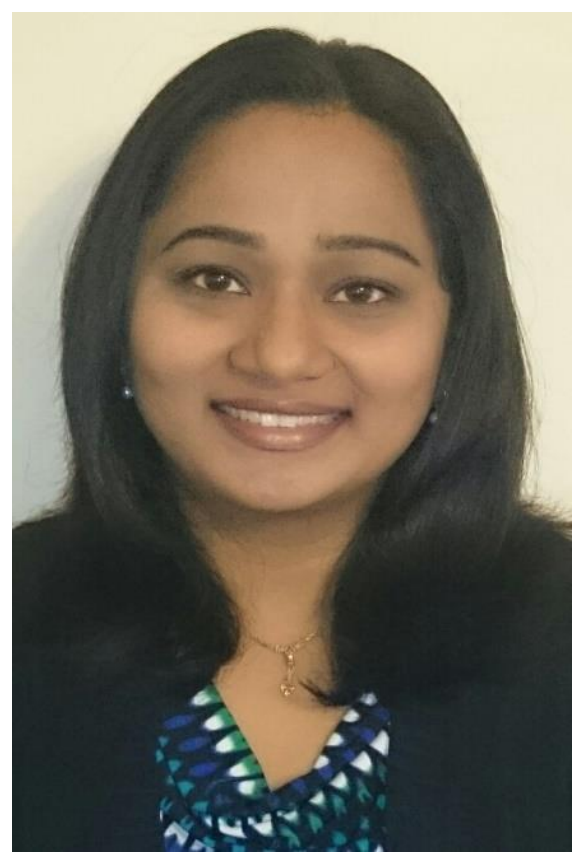

Dr. Vijayalakshmi Velusamy is a Senior Lecturer in Electronic Engineering in the Division of Electrical and Electronic Engineering at Manchester Metropolitan University, UK. She holds a PhD (2012) in DNA Biosensor Development from University of Limerick, Ireland, Master's degree (2007) in Micro and Nanotechnology from University of Ulster, UK and a Bachelor's degree (2002) in Electrical and Electronic Engineering from Bharathiar University, India. Her multidisciplinary research focuses on the development of novel integrated sensors/biosensors for a wide range of applications such as environmental monitoring, biosecurity, wearable devices, disease biomarker detection and point-of-care and smart medical devices.

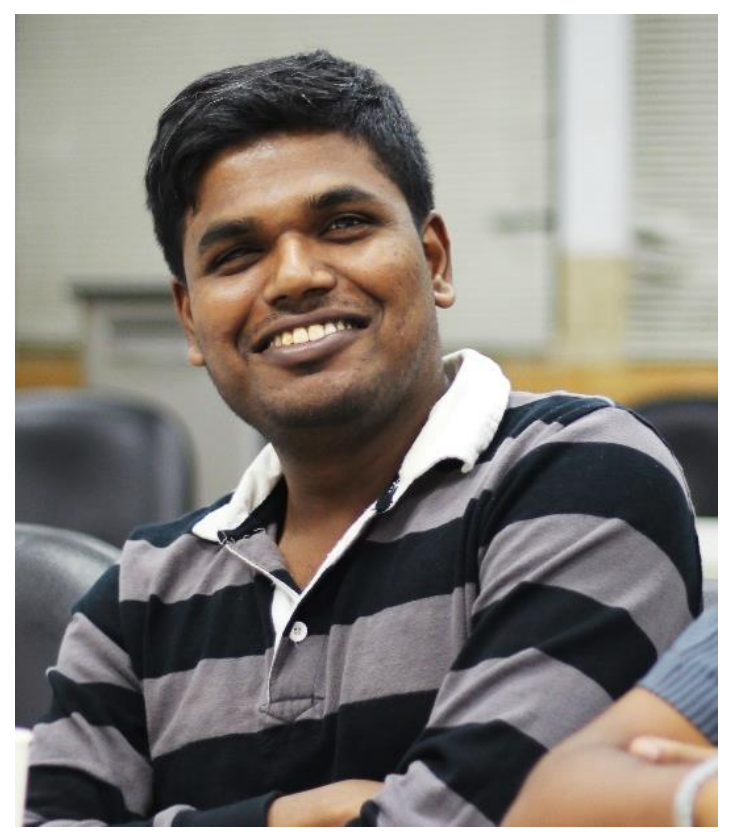

Dr. Selvakumar Palanisamy received his B.Sc (2006), M.Sc (2009) and M. Phil (2010) degrees in Chemistry from Madurai Kamaraj University, Tamilnadu, India. He obtained his PhD degree (2014) in Chemical Engineering from National Taipei University of Technology (NTUT), Taiwan. Currently, he is working as a post-doctoral fellow in Prof. Shen-Ming Chens' lab at NTUT. His current research interest include the synthesis of nanomaterials and applications related to the electrochemical sensors and biosensors. He has 
published over 75 research articles in SCI journals. He also serves as a consulting editor of Journal of reports in electrochemistry.

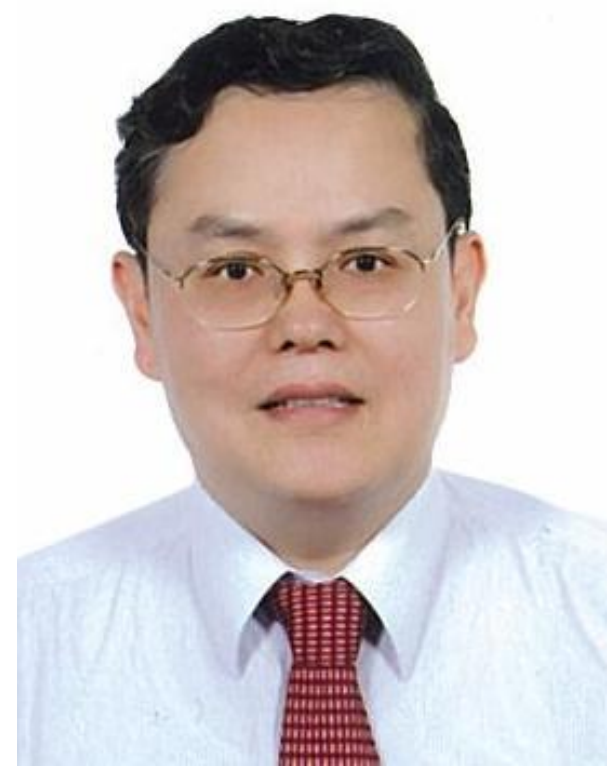

Dr. Shen-Ming Chen received his B.S. Degree in Chemistry in 1980 from National Kaohsiung Normal University, Taiwan. He received his M.S. Degree (1983) and Ph.D. degree (1991) in Chemistry from National Taiwan University, Taiwan. He is currently a professor at the Department of Chemical Engineering and Biotechnology, National Taipei University of Technology, Taiwan. His current research interests include electroanalytical chemistry, bioelectrochemistry, fabrication of energy conservation and storage devices and nanomaterial synthesis for electrochemical applications. He has published more than 550 research articles in SCI journals.

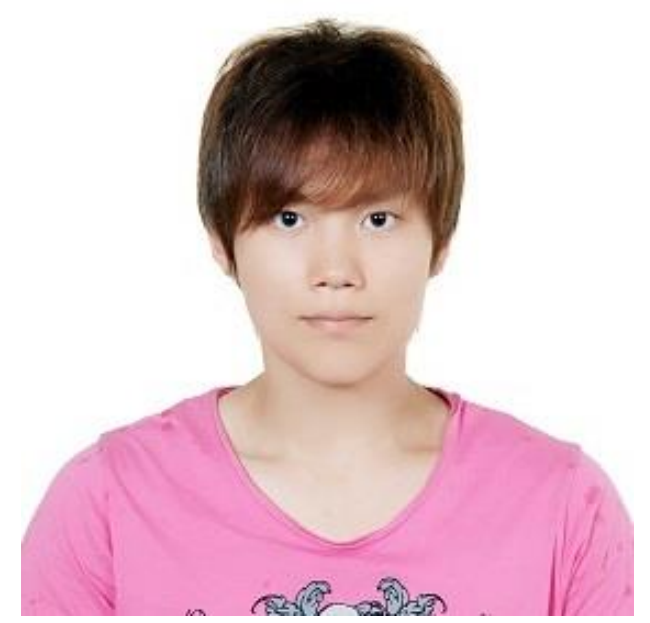

Mr. Tse-Wei Chen received his B.Sc. (2016) degrees in chemistry from $\mathrm{Fu}$ Jen Catholic University, Taiwan. Currently, he is a M.S. student in the department of Chemical Engineering and Biotechnology at National Taipei University of Technology. He specializes in electrochemical sensors and biosensors based on modified electrodes. His research interest also includes the synthesis of nanomaterials for different applications including graphene based composites. 


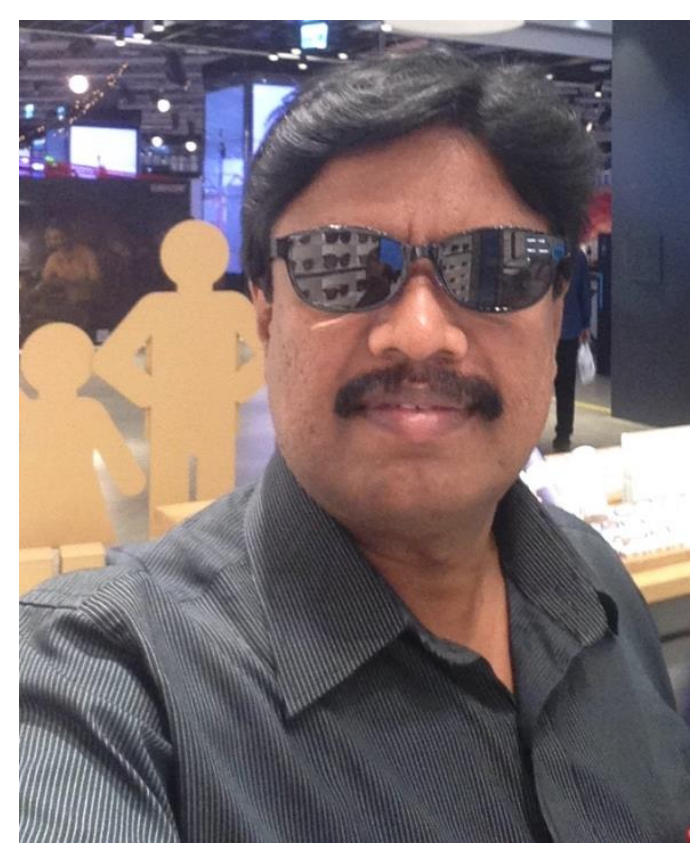

Dr. Sayee Kannan Ramaraj received his M.Sc. (1992) degree in Chemistry from Madurai Kamaraj University. He was the gold medalist in Master of Philosophy in School of Chemistry, Madurai Kamaraj University. He obtained his Ph.D. (2003) in School of Chemistry, Madurai Kamaraj University. He is currently an assistant professor at the Department of Chemistry, Thiagarajar College, Madurai, India. He is also a visiting professor at the National Taipei University of Technology, Taiwan. He specializes in polymeric composites, Corrosion science, electrochemical sensors and biosensors.

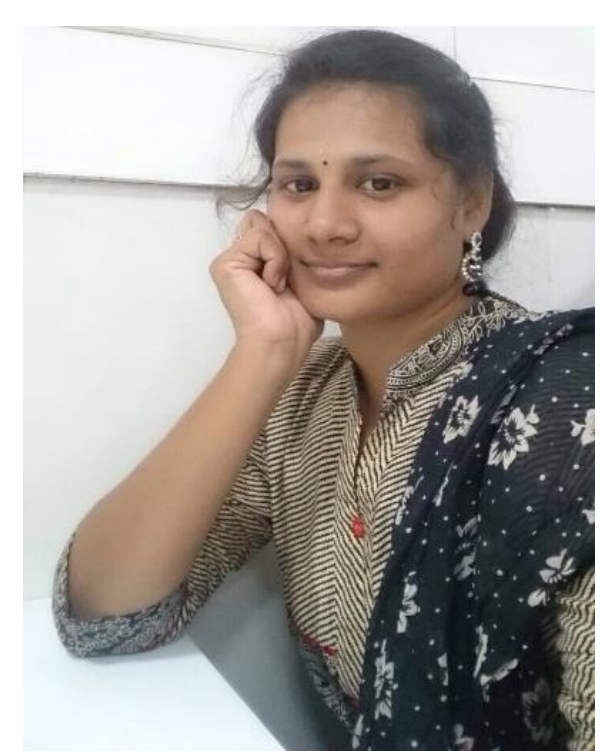

Ms. Sonadevi Selvam received her B.Sc degree (2010) from Sri Meenakshi College for Women in Madurai, Tamil Nadu, India. She received her M.Sc degree (2012) from VVV College for Women, Virudhunagar, Tamil Nadu, India. She obtained her M.Phil. degree (2013) from NMSSVN College, Madurai. Currently she is working as an Assistant professor in Department of Chemistry, PSR Engineering College, Sevalpatti, Sivakasi. Her research interest mainly focuses on the synthesis of nanomaterial for electrochemical sensors, biosensors and energy devices. 


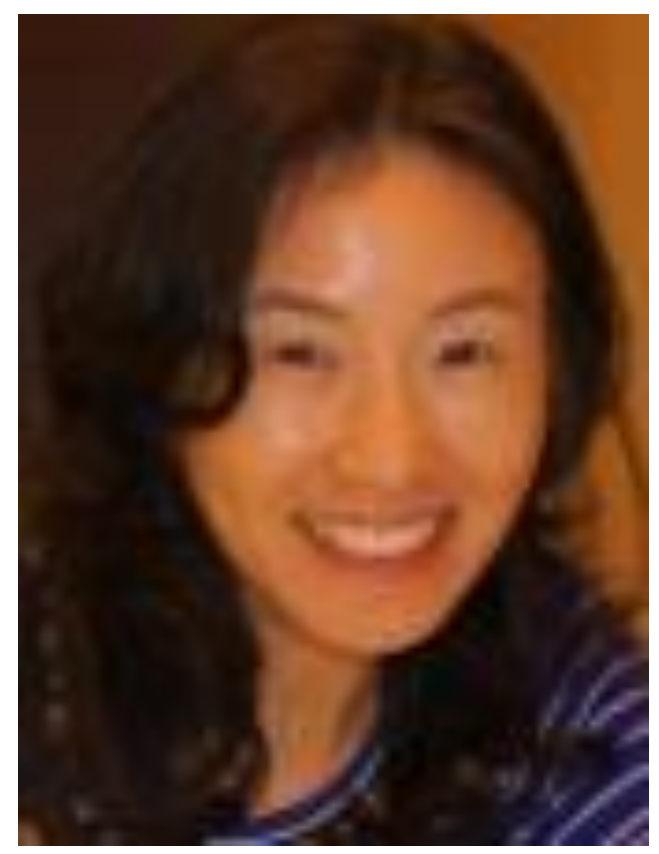

Dr. Bih-Show Lou received her B.S. Degree in Chemistry in 1984 at the National Kaohsiung Normal University, Taiwan. She then went to University of New Mexico, USA where she received her Ph.D. with Prof. Mark R. Ondrias in Biophysical Chemistry in 1993, then was a postdoctoral fellow at University of Arizona with Victor J. Hruby, Regents Professor. She is currently a professor at the Chemistry Division, Center for General Education, Chang Gung University, Taiwan. Her current research interests include spectroscopy for chemical and nanomaterial analysis, bioelectrochemistry for electrochemical and biosensor applications. 


\section{Figure captions}

Scheme 1 Schematic representation of the fabrication of $\mathrm{Hb}$ immobilized GR-CMF biosensor and its electrochemical reduction of $\mathrm{H}_{2} \mathrm{O}_{2}$.

Figure 1 SEM images of GR (A), CMF (B), GR-CMF composite (C). D) The corresponding optical images of GR dispersed in DMF (a), CMF (b) and GR dispersed in CMF after six days storage.

Figure 2 Elemental mapping of carbon (A) and oxygen (B) in GR-CMF composite.

Figure 3 A) FTIR spectra of CMF (a), GR (b) and GR-CMF composite (c). B) Raman spectra of pristine GR (a) and GR-CMF (b).

Figure $4 \mathrm{CV}$ response of $\mathrm{Hb}$ immobilized on CMF (a), GR (b) and GR-CMF composite (c) modified electrodes in $\mathrm{pH} 7$ at a scan rate of $100 \mathrm{mV} / \mathrm{s}$.

Figure 5 A) Amperometric $i$ - $t$ response of $\mathrm{Hb}$ immobilized GR-CMF modified RDE for the different concentration additions $(0.05-976 \mu \mathrm{M})$ of $\mathrm{H}_{2} \mathrm{O}_{2}$ into the constantly stirred $\mathrm{pH} 7$ with a working potential of $-0.3 \mathrm{~V}$. Upper inset shows the amperometric response of $\mathrm{Hb}$ immobilized GR-CMF modified RDE for the addition of $0.05,0.1,0.5,1.0,3.0$ and $5.0 \mu \mathrm{M} \mathrm{H} \mathrm{H}_{2} \mathrm{O}_{2}$ into the constantly stirred $\mathrm{pH}$ 7. Lower inset is the linear plot for amperometric current response vs. $\left[\mathrm{H}_{2} \mathrm{O}_{2}\right]$. B) Amperometric $i$ - $t$ response of $\mathrm{Hb}$ immobilized GR-CMF modified RDE for the addition of 1 $\mu \mathrm{M} \mathrm{H}_{2} \mathrm{O}_{2}$ (a), and $100 \mu \mathrm{M}$ additions of ascorbic acid (b), dopamine (c), uric acid (d), epinephrine (e), l-cysteine (f), norepinephrine (g) and glucose (h) into the constantly stirred $\mathrm{pH} 7$. Working potential $=-0.3 \mathrm{~V}$. C) Operational stability of the Hb immobilized GR-CMF modified RDE for the addition of $100 \mu \mathrm{M} \mathrm{H}_{2} \mathrm{O}_{2}$ in $\mathrm{pH} 7$ with a working potential of $-0.3 \mathrm{~V}$. 


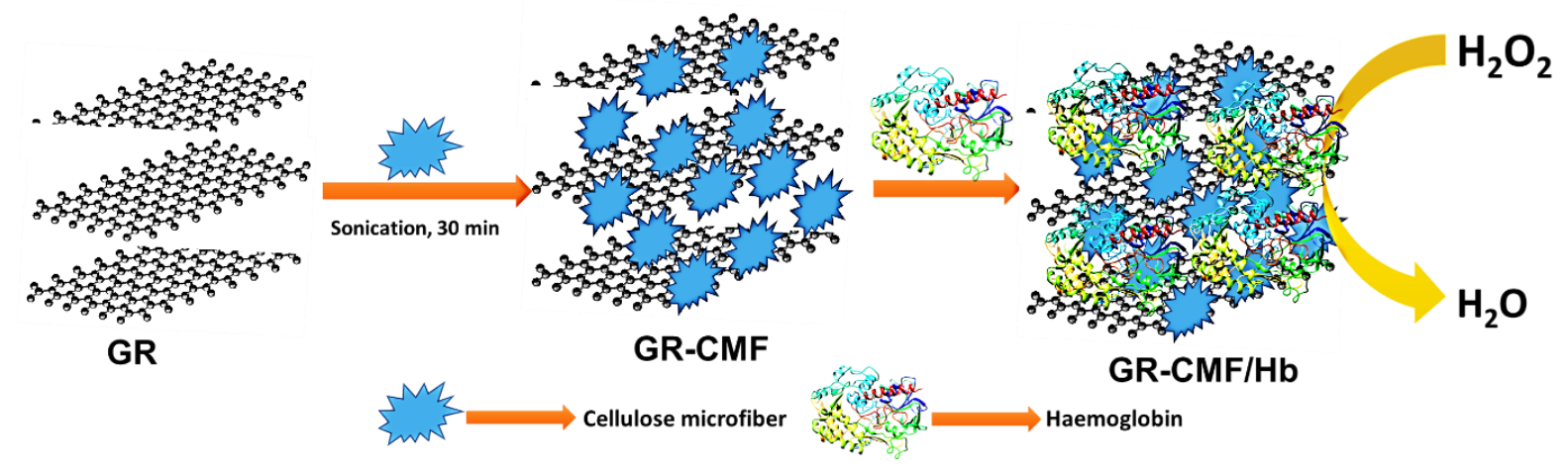

Scheme-1 


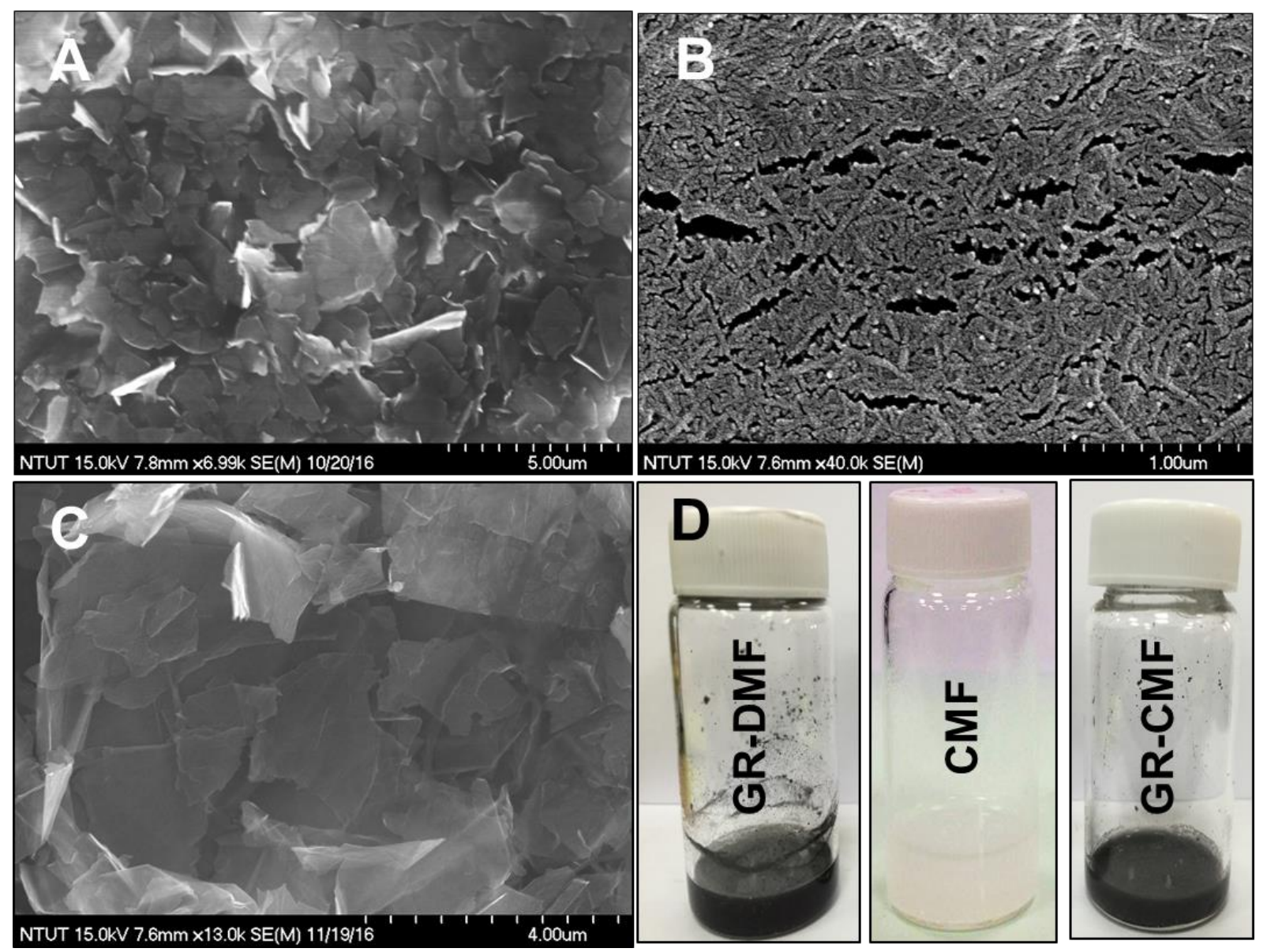

Figure-1 

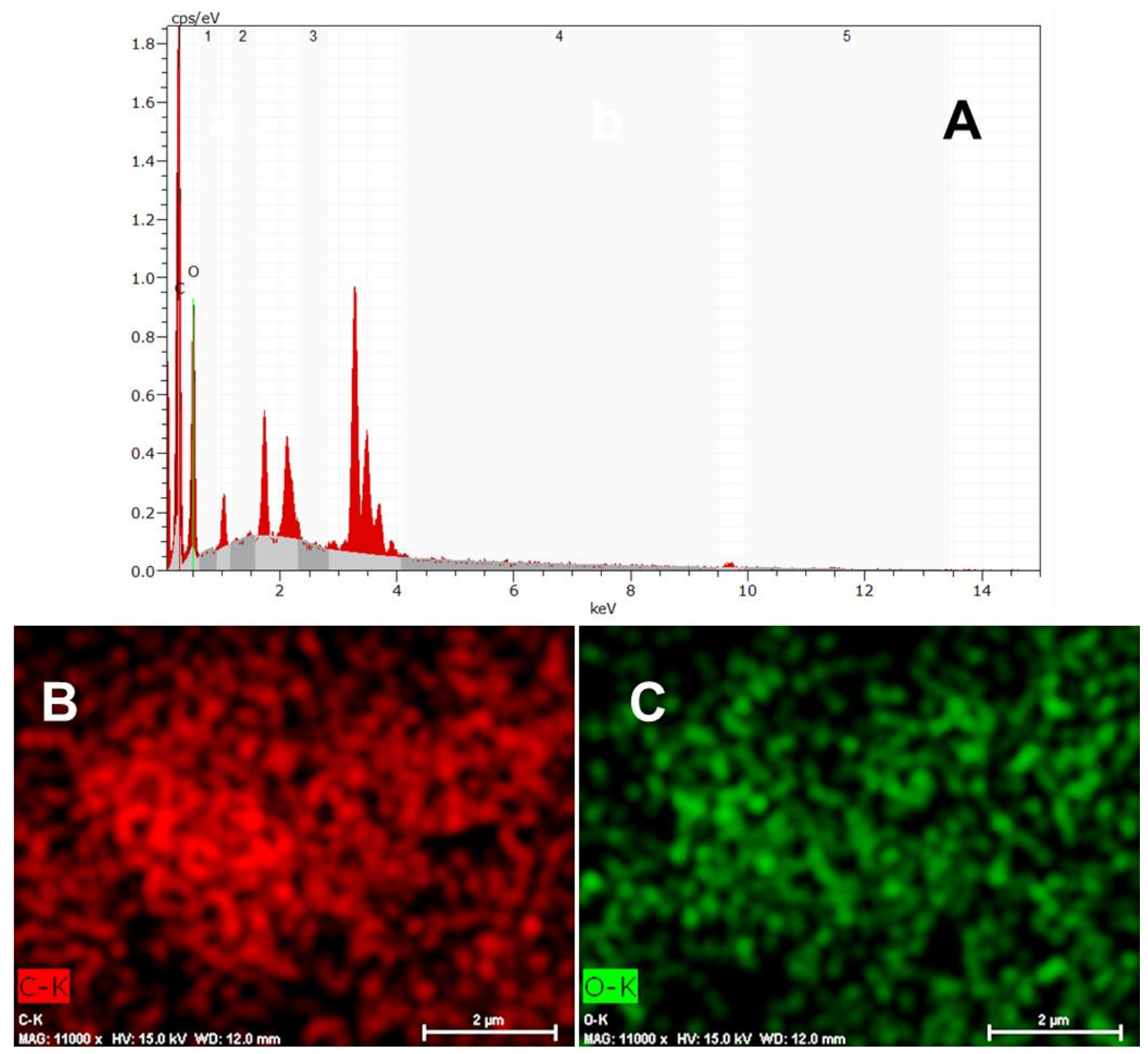

Figure-2 

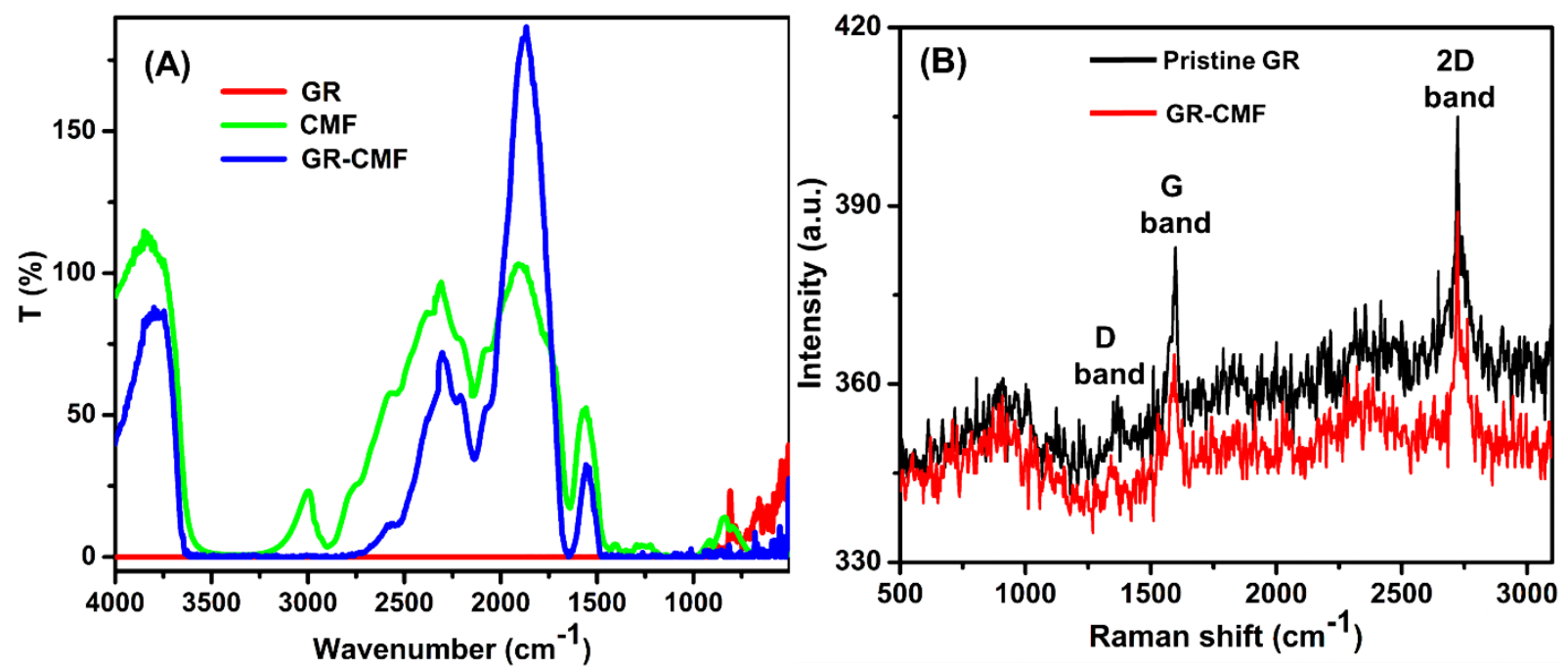

Figure-3 


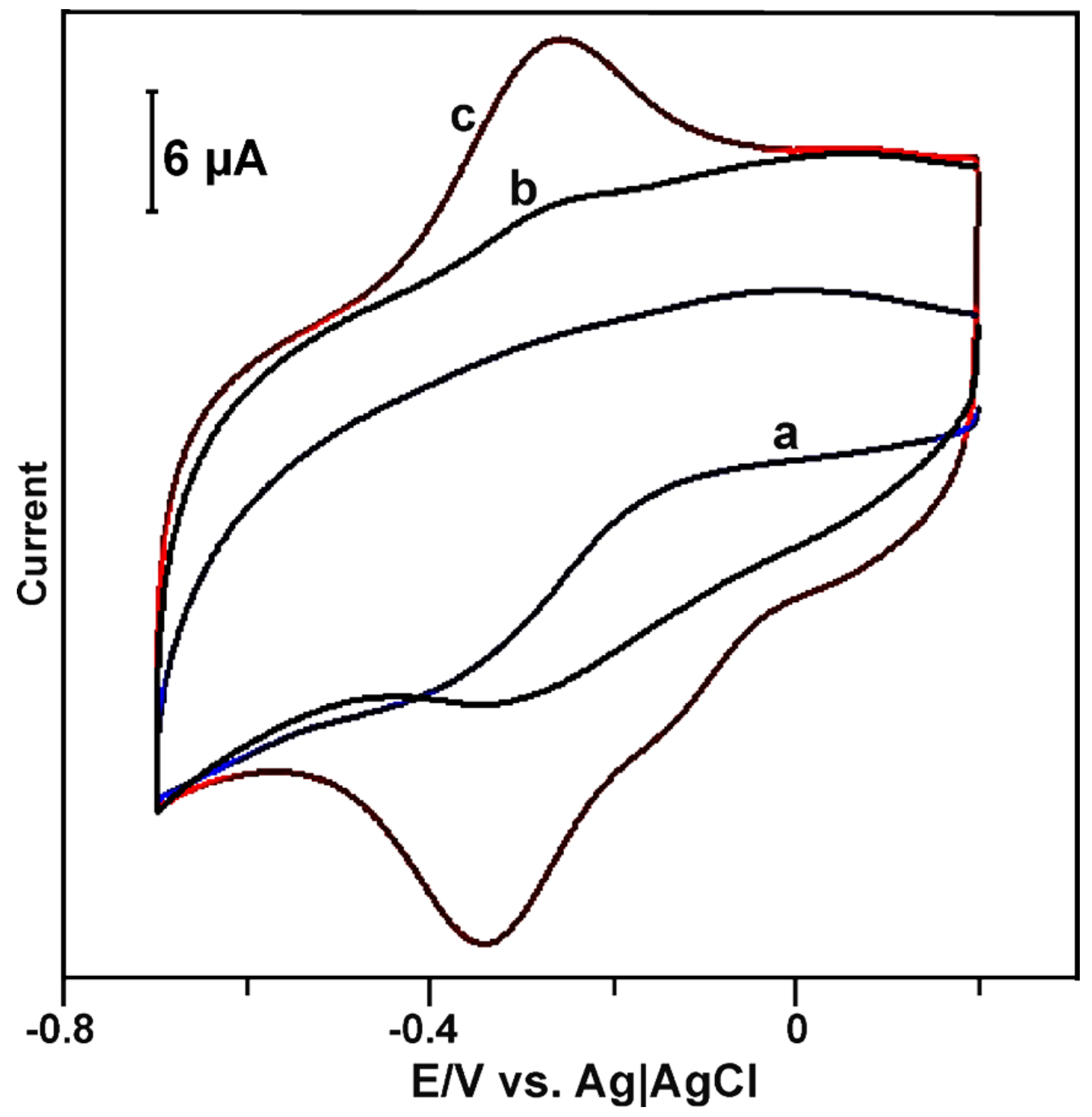

Figure-4 


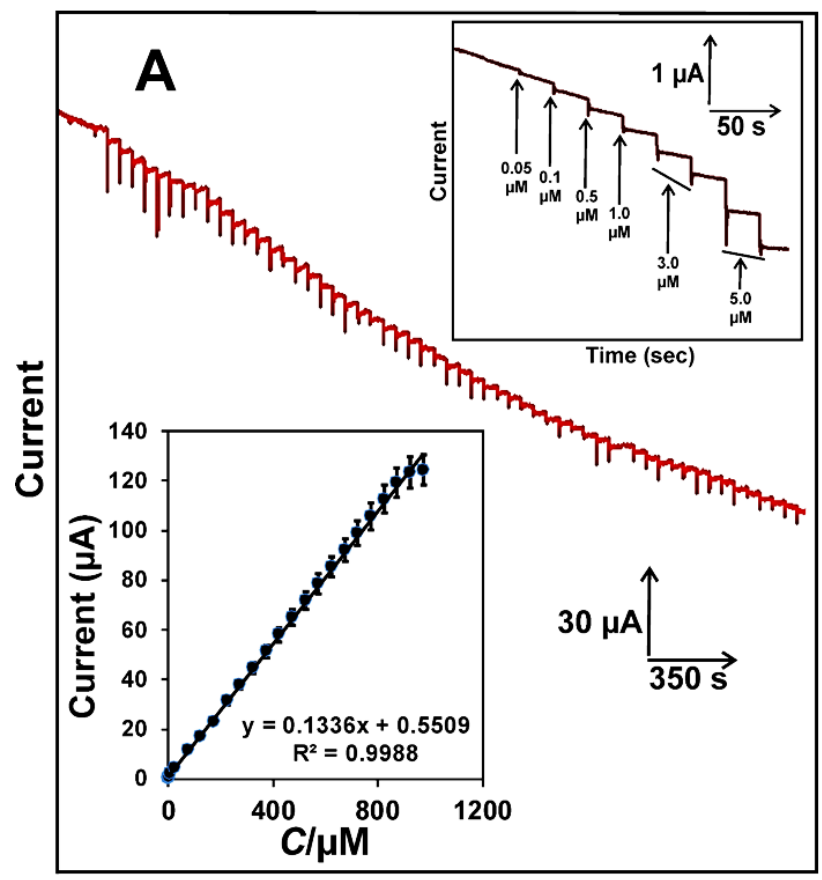

Time (sec)

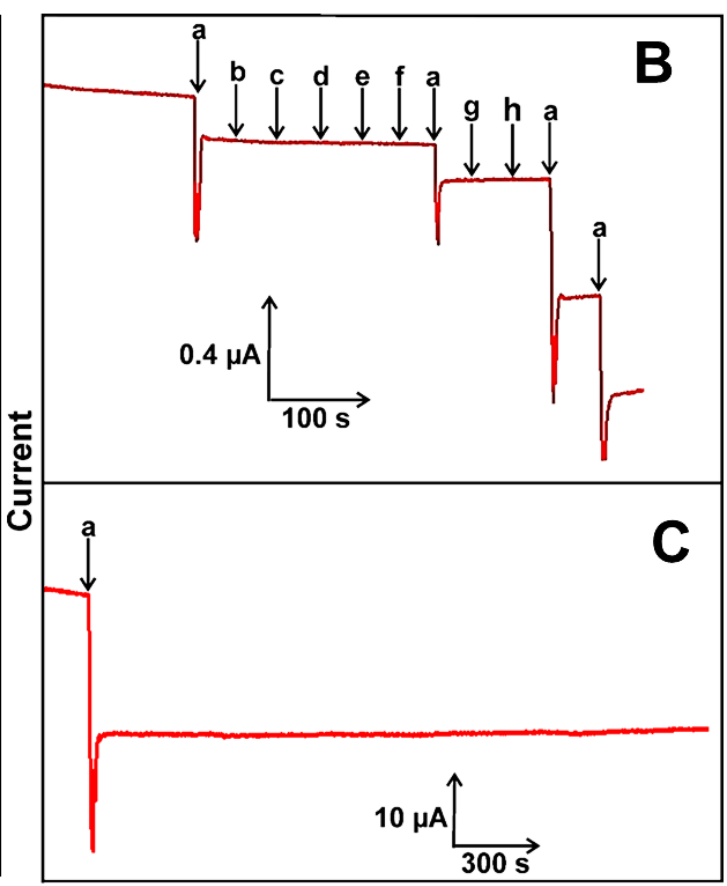

Time (sec)

Figure-5 